To appear in: International Journal of Modern Physics C

\title{
To sell or not to sell? Behavior of shareholders during price collapses
}

\author{
Bertrand M. Roehner ${ }^{1}$ \\ L.P.T.H.E. University Paris 7
}

\begin{abstract}
It is a common belief that the behavior of shareholders depends upon the direction of price fluctuations: if prices increase they buy, if prices decrease they sell. That belief, however, is more based on "common sense" than on facts. In this paper we present evidence for a specific class of shareholders which shows that the actual behavior of shareholders can be markedly different. For instance, they may continue to buy despite a prolonged fall in prices or they may sell even though prices climb. A closer analysis shows that a substantial proportion of investors are more influenced by the "general social climate" than by actual price changes. The percentage of speculative investors who optimize their portfolio on a monthly basis can be estimated and turns out to be about 5 to 10 percent. The results presented in this paper can be of usefulness in order to test the assumptions or the results of market simulations and models.
\end{abstract}

\section{January 2001}

Keywords: Stock prices, supply and demand, equity funds, inflow-outflow

1: Postal address: LPTHE, University Paris 7, 2 place Jussieu, 75005 Paris, France.

E-mail: ROEHNER@LPTHE.JUSSIEU.FR

FAX: 33144277990 


\section{Introduction}

"[Between March and May 2000] the hugely popular OTC and Emerging fund-management firm has lost 55 percent of its value; and yet new money continues to be invested in it, albeit at the rate of 50 million dollars a week, instead of some 200 million dollars."

We placed this excerpt from the Economist (27 May 2000) at the beginning of this paper in order to show on a specific example that even in the age of Internet communication and on line trading not all shareholders react to adverse news within days. One of the main objectives of this paper is precisely to estimate the proportion of the quickly reacting investors.

In order to fulfill that program we must focus on a specific class of shareholders. Indeed, to our knowledge, the only published figures regarding flows of money into or out from stock markets are those for investors who own stocks through mutual funds. Subsequently such shareholders will be referred to as mutual fund shareholders or more shortly as mf shareholders. The fact that one can know the net flow of money in the weeks, months or years following a stockprice collapse is of central importance for the present study. Subsequently in-flows will be counted positively and outflows negatively.

To begin with, let us briefly give some general information about American mutual funds. In 1999 there were about 8,000 funds of which bond funds represented 30 percent and equity funds (also called stock funds) about 50 percent (Mutual Fund Factbook 2000). The total assets of equity funds represented 2.4 trillion dollars in 1997 that is to say 25 percent of the capitalization of the New York Stock Exchange (NYSE) or 20 percent of the combined capitalization of the NYSE and NASDAQ (Statistical Abstract of the United States 1999). These orders of magnitude show that the impact of $\mathrm{mf}$ shareholders is far from being marginal. The $\mathrm{mf}$ shareholders are either households or institutions; in 1999 the latter (mainly retirement funds) represented one third of the assets.

\subsection{Formulation of the problem}

Table 1a gives monthly data for in-flows of new money into equity funds for the years 1997-2000. But how should these data be interpreted? That is what we want to discuss in the present paragraph. In order to simplify the discussion we consider the two following sorts of investors.

- The class of what we call speculative investors who optimize their investments on a daily or weekly basis. For instance, if the return of stock markets in a given month is negative while at the same time it is possible to get an annual 6 percent interest on bond markets they will make an arbitrage in favor of the later and shift a substantial part of their assets to the bond market.

- The class of what we call long-term investors who make their decisions on a multi-annual basis.

In real life there is probably a whole spectrum of attitudes between these borderline cases. It is mainly for the sake of simplicity that we restrict ourselves to these two classes. A convenient way to describe an actual population in that simplified framework is to consider that it is a mix of speculative and long-term investors. One of the key variables in the present study is the percentage represented by each class and one of our main goals is to get reliable estimates for them.

Now let us see on the specific example of the monthly data for 2000 how the above framework can be put to use. Two observations are in order. (i) For almost all months (with the only exception of August) the yields of bonds (either short-term or long-term) were higher than stock market returns. Thus, if all $\mathrm{mf}$ shareholders had been speculative investors they would have channeled their money into the bond market (or toward other lucrative markets such as for instance the real estate market which experienced a boom in 2000). In other words the in-flow of new money would have stopped or 
would even have become negative. In contrast the evidence shows that there was a total net in-flow of 290 billion dollars for 2000, which proves that some $\mathrm{mf}$ shareholders are rather long-term investors.

(ii) If one computes the regression between stock price changes $(\Delta p / p)$ and net in-flows of money $(f)$ one obtains (correlation is 0.57 ):

$$
f=a \Delta p / p+b \quad a=1.36 \pm 1.35 \quad b=25 \pm 7
$$

which shows that there is a definite relationship between flows and price changes. Incidentally it can be noted that whereas the error margin for $a$ is fairly high in the present case (this is because the regression is made on only 10 points) it is somewhat smaller for previous years (see table $1 \mathrm{~b}$ ). Equation (1) shows that the population of shareholders does not comprise 100 percent long-term investors (otherwise $f$ would not change with $\Delta p / p$ ).

More specifically it is possible to derive an estimate of the proportion $\alpha$ of speculative investors from equation (1). Indeed, under the assumption of two classes of investors the flow $f$ would be given by:

$$
f / k=\alpha(\Delta p / p)+(1-\alpha) \cdot 1
$$

$k$ denotes a proportionality constant between $f$ and the price changes; if $\alpha=1$ equation (2) reduces to: $f / k=\alpha \Delta p / p$ which means that the in-flows of money would be completely controlled by price changes; on the contrary if $\alpha=0$ they would be independent of price changes.

Identifying equations (1) and (2) gives:

$$
\frac{a}{\alpha}=\frac{b}{1-\alpha} \Longrightarrow \alpha=\frac{a / b}{1+a / b}
$$

With the data for 2000 this leads to: $\alpha=0.054 /(1+0.054)=5.1$ percent.

Incidentally it can be observed that if $a / b$ is small with respect to 1 one has approximately: $\alpha=a / b$. For other years (table 1b) one obtains estimates for $\alpha$ which are in the (5\%,10\%) range. Such an order of magnitude is consistent with what is known about the behavior of $\mathrm{mf}$ shareholders through surveys (see below).

\subsection{Some methodological points}

In the previous paragraph a number of methodological options have been selected which deserve a more detailed discussion.

(i) In considering portfolio optimization we neglected transactions costs. Was that justified? For stocks, transaction costs have notably declined in the 1990s (for more details see Roehner 2001, p.115); in the late 1990s they were of the order of one cent per share that is to say about 0.2 percent. For equity funds the decline was much slower however. In 1990 transaction costs represented about 1.8 percent and by 1998 they had declined to 1.3 percent (Reid 2000, p.18). Since the return differential between stocks and bonds was in 2000 at least 6 percent, even such high transaction costs cannot deter speculative investors from moving their money from one market to another; however it certainly induces much friction and partly explains the reluctance of mf shareholders to switch to a different investment strategy.

(ii) In so far as equity funds comprise American as well as foreign stocks one may wonder if one should not use a world index for stock prices. In fact, throughout the 1990s foreign stocks represented only about 10 percent of the total assets of American equity funds: the figure was 11 percent in 1990 and 13 percent in 1999 (Reid 2000, p.14).

(iii) One may wonder why the stock prices and money flows in table 1a were not corrected for inflation. In fact such a correction would be quite negligible: during the 1990s the annual inflation rate 
was on average less than 2 percent which means that on a monthly basis it was less than 0.2 percent. Such a correction is far smaller than the error margin on the flow data. However, when subsequently we consider yearly data over the whole decade we use deflated figures (over the decade the price increase was about 30 percent).

(iv) A last point concerns the fact that we used $f$ as our dependent variable instead of $\Delta f / f$ or some other measure of fluctuations such as the difference between monthly values and the overall trend (for instance in the form of a moving average). In fact the regressions were also carried out for $\Delta f / f$, with basically similar results. We preferred using $f$ because this is already an increment: it represents the change in the funds assets, $\Delta f / f$ would be a second-order increment. Furthermore to use the difference between monthly values and a trend would mean that we renounce to explain the trend; this would simply disregard the low-frequency response of long-term investors.

Table 1a Net new money invested in equity mutual funds versus stock price changes, monthly data

\begin{tabular}{|c|c|c|c|c|c|c|c|c|c|c|c|c|}
\hline & Jan. & Feb. & Mar. & Apr. & May. & Jun. & Jul. & Aug. & Sep. & Oct. & Nov. & Dec. \\
\hline \multicolumn{13}{|l|}{1997} \\
\hline $\mathrm{NY}+\mathrm{NAS}(\%)$ & & -0.23 & -4.6 & 4.3 & 7.0 & 4.4 & 7.6 & -3.9 & 5.8 & -3.7 & 3.1 & 1.6 \\
\hline $\begin{array}{c}\text { Flows (bls \$) } \\
\mathbf{1 9 9 8}\end{array}$ & 28 & 17 & 10 & 16 & 20 & 16 & 26 & 14 & 25 & 20 & 18 & 15 \\
\hline $\mathrm{NY}+\mathrm{NAS}(\%)$ & & 7.2 & 4.8 & 1.1 & -2.6 & 3.2 & -2.0 & -16 & 6.7 & 7.1 & 6.2 & 6.1 \\
\hline $\begin{array}{c}\text { Flows (bls \$) } \\
1999\end{array}$ & 14 & 24 & 22 & 26 & 18 & 19 & 19 & -11 & 6.2 & 2.4 & 13 & 3.2 \\
\hline $\mathrm{NY}+\mathrm{NAS}(\%)$ & & -3.8 & 4.0 & 4.7 & -2.1 & 5.3 & -3.0 & -0.65 & -2.3 & 6.2 & 4.3 & 9.3 \\
\hline $\begin{array}{c}\text { Flows (bls } \$ \text { ) } \\
\mathbf{2 0 0 0}\end{array}$ & 17 & 0.76 & 12 & 26 & 15 & 19 & 12 & 9.4 & 11 & 21 & 18 & 25 \\
\hline NYSE (\%) & & -4.6 & 9.3 & -0.46 & -0.15 & -0.31 & -0.15 & 5.3 & -1.6 & 0.45 & -5.5 & \\
\hline NASDAQ (\%) & & 19.2 & -2.6 & -15.5 & -11.9 & 16.6 & -5.0 & 11.7 & -12.7 & -8.2 & -22.9 & \\
\hline $\mathrm{NY}+\mathrm{NAS}(\%)$ & & 4.5 & 5.0 & -5.3 & -3.6 & 5.2 & -1.7 & 7.4 & -5.0 & -2.0 & -9.8 & \\
\hline Flows (bls \$) & 41 & 53 & 39 & 34 & 17 & 22 & 17 & 23 & 17 & 19 & 5.7 & \\
\hline Bond 3-mo.(\%) & 5.5 & 5.7 & 5.9 & 5.8 & 6.0 & 5.9 & 6.1 & 6.3 & 6.2 & & & \\
\hline Bond 10-yr.(\%) & 6.7 & 6.5 & 6.3 & 6.0 & 6.4 & 6.1 & 6.0 & 5.8 & 5.8 & & & \\
\hline
\end{tabular}

Sources: Stock indexes: http://finance.yahoo.com; bond yields: http://www.fms.treas.gov/bulletin; flows: Mutual Fund Factbook (2000)

Table 1b Regression of monthly flows $(f)$ with respect to price changes $(\Delta p / p): f=a \Delta p / p+b$

\begin{tabular}{cccccc}
\hline \hline Year & $a$ & $b$ & Correlation $\begin{array}{c}\text { Proportion } \alpha \\
\text { of speculative } \\
\text { investors }\end{array}$ \\
\cline { 2 - 6 } 1997 & $0.70 \pm 0.50$ & $16 \pm 2$ & 0.67 & $4.1 \%$ \\
1998 & $0.70 \pm 0.97$ & $11 \pm 6$ & 0.42 & $5.7 \%$ \\
1999 & $1.36 \pm 0.61$ & $12 \pm 3$ & 0.82 & $9.9 \%$ \\
2000 & $1.36 \pm 1.35$ & $25 \pm 7$ & 0.57 & $5.1 \%$ \\
\hline \hline
\end{tabular}




\subsection{Short-term response (weekly fluctuations)}

\subsubsection{Crash of August 1998}

Between 1 July and 30 September 1998 the Dow Jones index lost 13 percent (table 2). How did mf shareholders react? As can be seen from table 1a the total inflow for July-September was markedly lower than in the same quarter of 1997, but it was still positive. There was only an outflow of money in one month, namely 11 billions of dollars in August, a reaction which is probably connected with the fact that the most spectacular crash occurred by the end of August: between 20 and 31 August the Dow Jones index lost 12 percent. However this flow $(f)$ of 11 billions represented only 11/2368 $=0.46$ percent of the total assets of equity funds $(A)$.

Table 2 Net outflows of money $(f)$ caused by stock market crashes: short term perspective, in percent of funds assets $(A)$

\begin{tabular}{lllcc}
\hline \hline Year & Dates of crash & $\Delta p / p$ & $f / A$ \\
& & percent & percent \\
\cline { 2 - 4 } 1987 & 16 Oct. - 20 Oct. & -23 & -2.1 \\
1990 & 15 Jul. - 15 Oct. & -21 & -1.8 \\
1994 & 22 March - 6 April & -7.0 & -0.28 \\
1994 & Latin American stocks & & \\
& 15 Dec. - 31 Dec. & -15 & -1.8 \\
1998 & 20 Aug. - 31 Aug. & -12 & -0.46 \\
\hline \hline
\end{tabular}

Notes: The crash of 15-31 December concerned only funds comprising Latin American stocks; it was due to the devaluation of the Mexican peso on 20 Dec. 1994. The linear regression for the five points in the table is: $f / A=a \Delta p / p+b, \quad a=0.11 \pm 0.06, \quad b=0.54 \pm 0.36$ (the correlation is 0.90 ) which gives $\alpha=17$ percent.

Sources: Mutual Fund Factbook (2000), Marcis et al. (1995)., Reid (2000).

\subsubsection{Crash of October 1987}

During the month of October 1987 the Dow Jones index lost 23 percent (table 2); in that month the reaction of $\mathrm{mf}$ shareholders resulted in an outflow of cash representing 3.1 percent of equity funds assets. In November the outflow was only 0.5 percent and for December the figure was almost the same. It is interesting to observe that 70 percent of the October outflow occurred in the three crashdays of October 16, 19, and 20 (Rea et al. 1996). Moreover a survey conducted in November 1987 by the Investment Company Institute shows that only 5 percent of the shareholders had sold shares during the crash. A survey conducted after the more limited crash of March 1994 similarly showed that only a small number (of the order of 5 percent) of mf shareholders had sold shares.

In short, the picture which emerges from the above observations shows that a majority of shareholders are long-term investors who do not care about short-term price fluctuations even when they assume crash proportions. This is in agreement with the opinion expressed by mutual fund managers: "A vast majority of shareholders are seasoned investors who do not intend to redeem [i.e. sell] shares in response to adverse market developments" (Rea et al. 1996).

Nevertheless, it would obviously be unreasonable to imagine that mf shareholders will hold their shares no matter what happens in the market whatsoever. To get a clearer view of that point we know analyze their response to fluctuations extending over one or several years. 


\subsection{Long-term response (yearly fluctuations)}

So far we have focused on daily fluctuations; in the present paragraph we consider fluctuations which have a typical duration of one or two years. Yearly data for the decade 1990-2000 are summarized in table 3a; they are not very conclusive however for there is almost no correlation between price changes and flows whether expressed in absolute or relative terms. A better procedure consists in slicing the interval 1942-1990 into sub-intervals (of an average duration of about two years) during which there was a steady price increase (or decrease) on an annual basis. For each sub-interval we want to know whether shareholders have sold or bought. The results are summarized in Fig.1 and table 3b. "Ideally" one would expect a relationship of the form:

$$
f / A=a \Delta p / p+b
$$

Table 3a Net new money invested in equity mutual funds versus stock price changes, annual data

\begin{tabular}{lccccccccccc}
\hline \hline & & & & & & & & & & & \\
& 1990 & 1991 & 1992 & 1993 & 1994 & 1995 & 1996 & 1997 & 1998 & 1999 & 2000 \\
\hline NYSE Composite & -7.7 & 22.5 & 4.7 & 7.9 & -3.1 & 31.6 & 15.3 & 30.4 & 16.8 & 8.3 & 0.9 \\
Flows, equity, (bl.\$ ) & 13 & 38 & 74 & 115 & 102 & 107 & 182 & 186 & 127 & 148 & 221 \\
& & & & & & & & & & & \\
Treas., 30-yr, yield (\% ) & 8.5 & 7.8 & 7.4 & 6.5 & 7.1 & 6.8 & 6.5 & 6.4 & 5.5 & 5.8 & 6.0 \\
Flows, bond, (bl.\$ ) & 7 & 57 & 66 & 65 & -55 & -5 & 2.5 & 23 & 60 & 4.7 & \\
\hline \hline
\end{tabular}

Notes: The flows are deflated and expressed in 1990 dollars. The regression between price change and flows reads (correlation is 0.22): $f=a(\Delta p / p)+b \quad a=1.1 \pm 3.1 \quad b=106 \pm 38$ which leads to $\alpha=1$ percent. Sources: Price index: http://minneapolis.org/economy; NYSE Composite: http://finance.yahoo.com; flows: Reid: Reid (2000); bond yield: http://www.fms.treas.gov/bulletin.

Table 3b Relationship between changes in stock prices $(\Delta p / p)$ and the net in- or out-flow of money $(f / A): f / A=a \Delta p / p+b, \mathbf{1 9 4 2 - 1 9 9 0}$

\begin{tabular}{lccccc}
\hline \hline Observations & $\begin{array}{c}\text { Number } \\
\text { of } \\
\text { observat. }\end{array}$ & $a$ & $b$ & \multicolumn{2}{c}{$\begin{array}{c}\text { Coef. of } \\
\text { correl. }\end{array}$} \\
& & & & & \\
\hline All data & 28 & $0.32 \pm 0.15$ & $5.4 \pm 7.3$ & 0.63 & $(0.34,0.81)$ \\
& & & & & \\
Bullish climate & 10 & $0.60 \pm 0.29$ & $-10 \pm 10$ & 0.82 & $(0.40,0.96)$ \\
Price increases & 10 & $-0.14 \pm 1$ & $5 \pm 7$ & -0.14 & $(0.69,0.56)$ \\
Price decreases & & & & & \\
Bearish climate & 4 & $-0.72 \pm 0.79$ & $10 \pm 9$ & -0.78 & $(-0.99,0.72)$ \\
Price increases & 4 & $0 \pm 0.5$ & $-5 \pm 6$ & 0.02 & $(-0.96,0.96)$ \\
Price decreases & 4 & & & & \\
\hline \hline
\end{tabular}

Notes: The figures within parenthesis give the confidence interval for the correlation at probability level 0.95. The regression for all data leads to $\alpha=5.6$ percent. 
where $a$ is positive and has (more or less) the same value whether $\Delta p / p$ is positive or negative. Such a relationship would mean that $\mathrm{mf}$ shareholders buy when prices increase and sell when they fall. However Fig. 1 shows that the regression line is not the same for positive and negative price changes. For price increases there is an unambiguous positive correlation and regression, whereas for price falls the regression coefficient is almost equal to zero. In other words, mf shareholders responded to price increases by buying new shares, but to price falls they reacted not by selling but by stopping to buy.

One can go a step further. Consider the points in the $\Delta p / p \geq 0$ region; there is an obvious cluster of outliers below the $f / A=0$ axis; these points correspond to cases for which shareholders responded to a price increase by selling, a rather puzzling behavior. A clue is the observation that all these events occurred during the bear market of 1970-1980. In other words in an overall bear climate shareholders sell whether the annual price changes are positive or negative.

Is there a mirror-effect during bull markets, that is to say, do shareholders buy during bull markets even when prices fall? We have already seen that this was the case in 2000. In Fig. 1 the points corresponding to such a behavior would be in the quadrant: $(\Delta p / p<0, f / A>0)$; not surprisingly all these cases occurred during bull market periods (marked by up-going arrows).

The regression coefficients corresponding to the anomalous cases of quadrants 2 and 3 are defined with large error margins due to the small number of cases in each sub-category; but, at least qualitatively there is no doubt as to the existence of the effects described above. In a sense one is here is the same situation as in neutrino physics in the late 1960s when the number of collision-events for an experiment campaign lasting several weeks was of the order of a few dozens. As in neutrino physics, in order to get better accuracy one needs more events.

\section{Conclusion}

According to economic theory the equilibrium price of a good is determined by the intersection of the supply $(S)$ and demand $(D)$ curves. For stock markets these curves are largely unknown however. On stock exchanges equilibrium prices are determined by computer codes and, for instance on the NYSE in the case of large transactions, by the intervention of the specialist in charge of that specific stock. Note that the supply and demand curves cannot be reconstructed from the knowledge of the trading volume $V=S+D$ and equilibrium prices. For that purpose one would need to know the bid-ask prices and bid-ask volumes, that is to say the prices and volumes on the demand and supply sides ( people wanting to buy versus people wanting to sell). Unfortunately these data are not made public and thus it is impossible to construct supply and demand curves for a given stock.

This is regrettable because models and simulations require specific assumptions to be made about the relationship between excess-supply (i.e. $s=S-D$ ) and the magnitude of the price changes (sign and amplitude). For instance in the Cont-Bouchaud model (Cont et al. 2000, Stauffer et al. 1999) it is assumed that the logarithm of the price changes in proportion to excess-supply. Since that relationship cannot be derived from observation it has to be conjectured which adds additional free parameters to the model. Note however that, in contrast to other models, the Cont-Bouchaud model does not make any specific assumptions regarding the response of agents to price changes: the decisions to buy or to sell are taken randomly.

In the present paper we have investigated the actual behavior of mf shareholders. In particular, we have seen that there is no simple relationship between price variation and propensity to buy or sell. What should be the next step? Obviously it would not be reasonable to jump too quickly to the conclusion that all shareholders have the same behavior as $\mathrm{mf}$ shareholders: inductive reasoning based on only one case is fairly hazardous. As we already emphasized, in order to make further 
progress one needs additional data. It is not impossible that evidence for other classes of shareholders may be available for instance in the publications of insurance companies or commercial banks. Once one knows the behavior of three or four classes of investors one will be in a much better position to make a reasonable inference about the form of the excess-supply function $s=s(p)$.

Acknowledgment: The paper greatly benefited from Dietrich Stauffer's critical reading and advice; many thanks to him. 


\section{References}

Cont (R.), Bouchaud (J.-P.) 2000: Herd behavior and aggregate fluctuations in financial markets. Macroeconomic Dynamics 4, 170.

Marcis (R.), West (S.), Leonard-Chambers (V.) 1995: Mutual fund shareholders response to market disruptions. Perspective 1,1 (July), published by the Investment Company Institute.

Rea (J.), Marcis (R.) 1996: Mutual fund shareholder activity during U.S. stock market cycles 19441995. Perspective 2,2 (March), published by the Investment Company Institute.

Reid (B.) 2000: The 1990s: A decade of expansion and change in U.S. mutual fund industry. Perspective 6,3 (July), published by the Investment Company Institute.

Roehner (B.M.) 2001: Hidden collective factors in speculative trading. Springer-Verlag. Berlin.

Stauffer (D.), Sornette (D.) 1999: Self-organized percolation model for stock market fluctuations. Physica A 271, N3-4, 496-506.

Figure caption

Fig.1 Net new money invested in mutual equity funds as a function of stock price changes. The dotted line shows the regression line for all points together; it can be seen that there are two clusters of outliers. The arrows indicate the bullish or bearish state of the market, as defined in the inset which shows the evolution of the Standard and Poor's index (a moving average was performed in order to highlight the trends). That additional variable accounts for the anomalous points in quadrants 2 $(x<0, y>0)$ and $3(x>0, y<0)$. Source: Rea et al. (1996). 


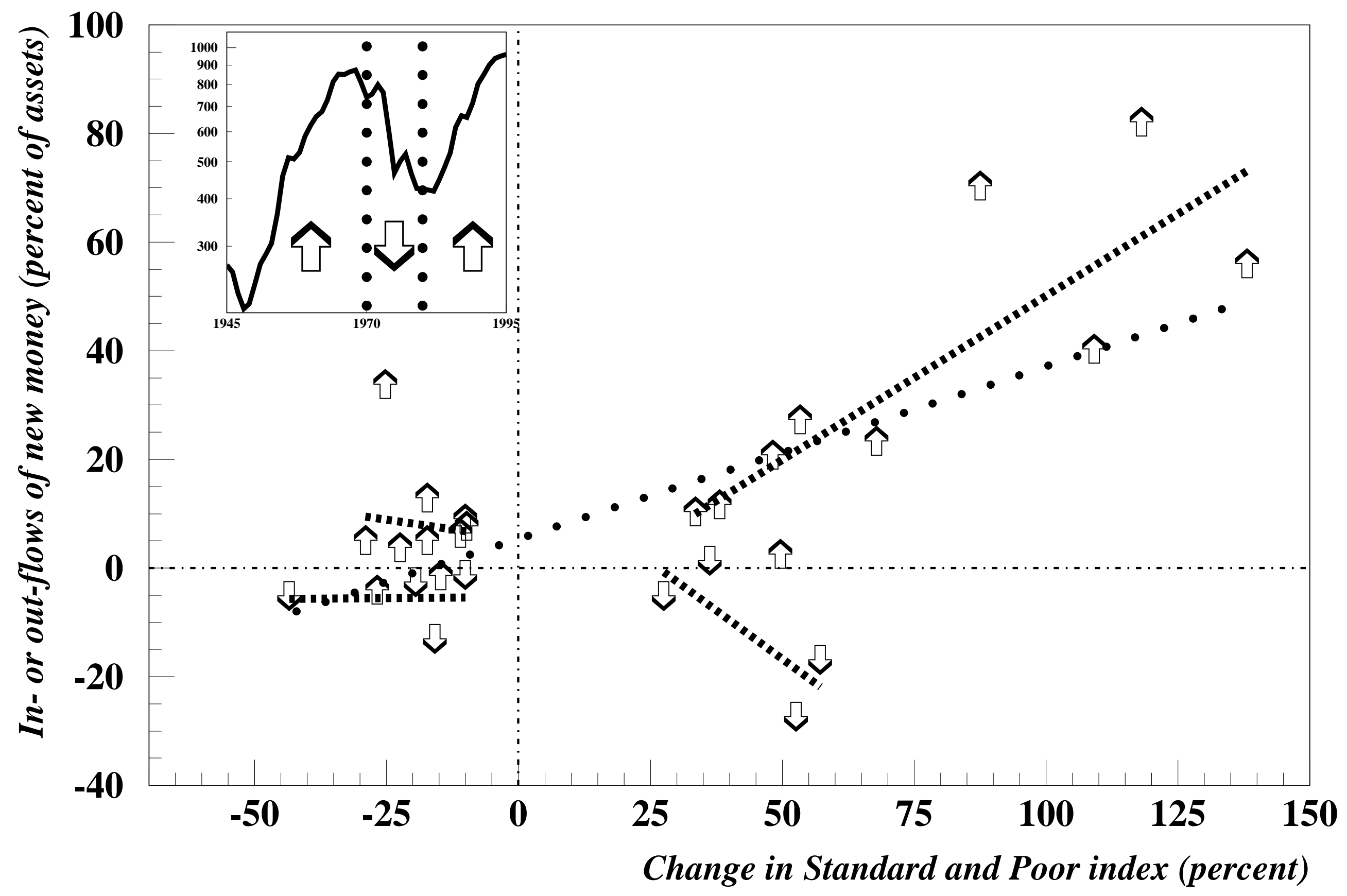

